present one only those objects have been retained which were most easily interpreted by the greatest number of children. Some objects which might seem to be very familiar to adults had to be rejected. For instance, an anchor which was easily recognised by boys presented difficulties to girls and had to be discarded. The objects retained are either easy to interpret or else capable of a varied interpretation so that the test is an estimate of the child's visual acuity and not of his intelligence.

Though the work is independent on my part yet I now find that the idea of an object test chart on the strictly Snellen principle is by no means original.

\title{
ARGYROSIS OF CONJUNCTIVA, CORNEA AND TEAR-SAC
}

\author{
BY
}

Professor Arnold Loewenstein, M.D.

(FROM THE DEPARTMENT OF OPHTHALMOLOGY, UNIVERSITY OF OF GLASGOW. PROF. A. J. BALLANTYNE)

THE deposition of silver particles on the conjunctiva is not at all rare. In countries where trachoma is endemic the use of silver drops is practised regularly, even without medical prescription, because of the relief experienced. One case is reported of a Czech farmer's wife who carried on treatment for twenty-two years (Knapová and Bruckner, 1922). Many oculists will be surprised at the length of time certain patients are using their prescriptions, the following being an example. A woman, aged 72 years, with cataract, incipient in one and more advanced on the other eye, was given argyrol ointment to be used for four days prior to operation. When she returned a year later she had a marked argyrosis, and it was discovered that she had used the ointment daily for the whole period. Successful intracapsular extraction failed to reveal any silver in the lens capsule.

Argyrosis of the conjunctiva arises not only after local use of silver, but also when this is administered orally and intravenously (Salus, 1917, Ascher, 1924), or in industrial diseases (Subal, Freyler, 1936), following treatment of nasal sinuses and after the use of silver to dye the beard, etc.

While argyrosis of the conjunctiva is frequent, corneal argyrosis is rarely mentioned (Ascher, Knapová and Bruckner, Vogt, Freyler, Kotsuka). My impression is that corneal argyrosis has been overlooked because it is not clinically conspicuous. 
There are some cases of argyrotic tear-sac already described (Gabrielides, 1934; Damel, 1934; Ciotola, 1937). Undoubtedly such changes of the tear-sac would be discovered more frequently in cases of conjunctival argyrosis if it were possible to examine the sac histologically.

A case which I followed clinically provided me with anatomical material from the conjunctiva and the tear-sac, and presents some interesting questions.

Mrs. H., aged 67 years, who complained of watering of the right eye for some years was treated with dark drops which she used twice daily for some months. Silver deposits were not visible except in the conjunctiva. Ectropion of the nasal part of the lower lid was present, and the inferior punctum was everted. On squeezing there was mucous discharge but no pus. The whole conjunctiva of the lower lid, the nasal part of the upper lid, and the entire bulbar conjunctiva, the caruncle included, was stained partly lead grey, partly chocolate brown. The bulbar conjunctiva was diffusely stained a bluish grey, the conjunctiva of the lids was brown and patchy. The caruncle was covered with minute cysts containing clear fluid, on its surface there was greyish-brown dust. With the small beam of the slit-lamp we could localise the dust below the epithelium. A drop of 2 per cent. dionine produced oedema and the pigment was raised with the epithelium. A minute greyish-brown spider-shaped network was situated in the oedematous fluid between the sclera and the epithelium. All these changes were more marked on the nasal than on the temporal side. No lymph vessels were visible either accompanying the blood vessels, or separate; and there was no dust surrounding the blood vessels suggesting the existence of lymph vessels (as Koeppe described in his text-book).

Macroscopically both corneae appeared normal. The left showed, with the slit-lamp, a tiny central cystic macula and normal corneal reflexes. With the narrow beam the right cornea gave a more intensive corneal beam appearing bluish-white in its posterior part. The region of Descemet's area was clearer shining than the anterior part of the cornea, this being more conspicuous in the lower half, but present in the upper corneal tissue as well.

With the broad beam Descemet's area showed rainbow colours with coarse grain, but without any special pattern. 'The deeper parts of the eye, lens, fundi, etc., were normal. V.A. R.E., 6/6. L.E., 6/12.

November 3, 1939. R.E. Ovoid excision of conjunctiva and superficial tarsal plate of $5 \mathrm{~mm}$. extent. Three stitches were inserted, desired effect being obtained.

January 20, 1940. R.E. Sac excised. Watering now greatly reduced. 
Anatomically the conjunctiva showed a diffuse sub-epithelial argyrosis leaving the epithelium entirely free of silver particles. These particles were not even present in a narrow subepithelial zone of varying diameter (Fig. 1). Most of the particles were distributed in long rows of fine droplets, some thicker than others, some in dark clusters with a diameter of 20-50 $\mu$, and with an appearance similar to a brown jellyfish with its tentacles. The silver infiltration was not equal in all places, at some areas $40-50 \mu$, at others $150-170 \mu$ deep. With the highest power (x10 eyepiece and oil immersion) we see more of the structure of these fibres. They may be in double contour (Fig. 2). The coarser droplets

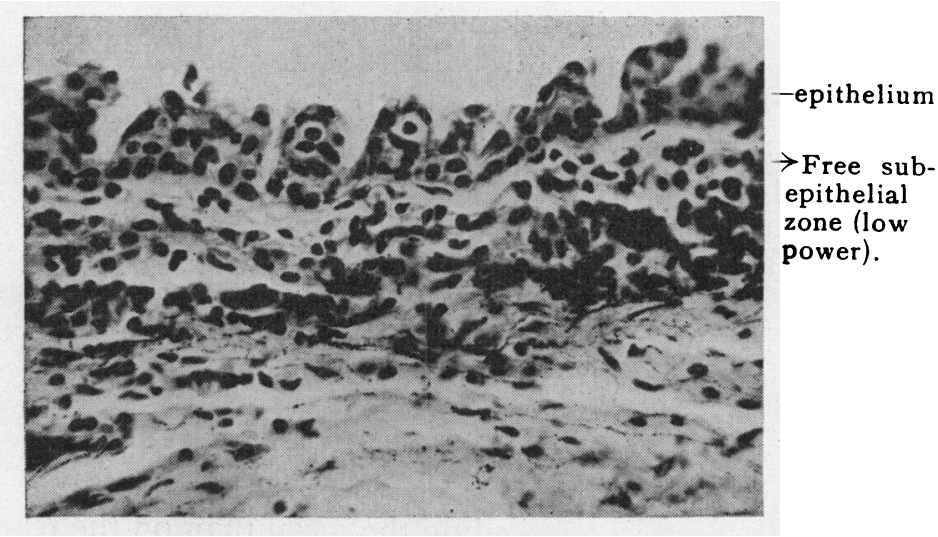

FiG. 1.

Granulated short coffee-brown fibres.

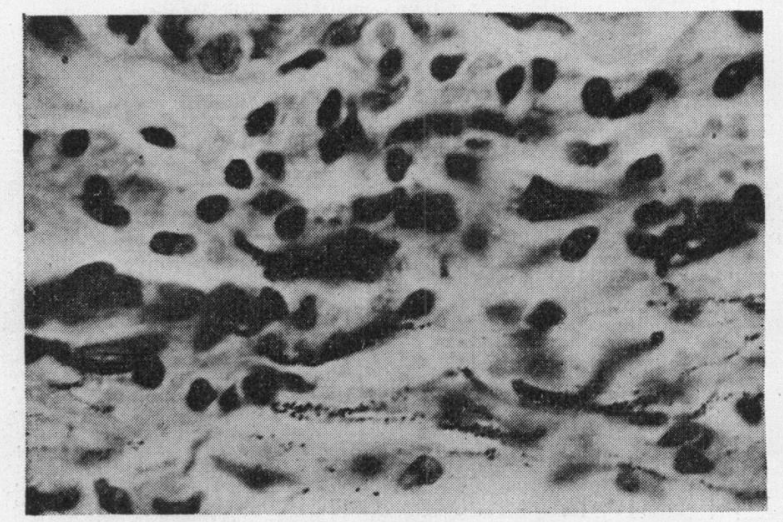

Fig. 2.

Tiny Ag. particles within fibrocytes. 10/40. High power. 


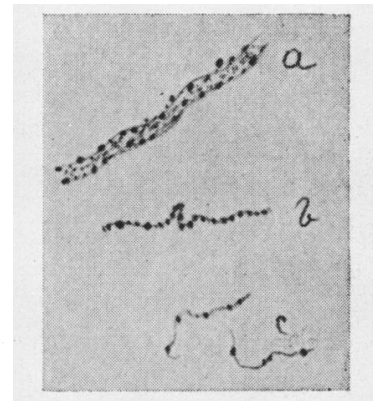

FIG. 3.

Conjunctival argyrosis. Three kinds of argyrotic fibres. 10/40

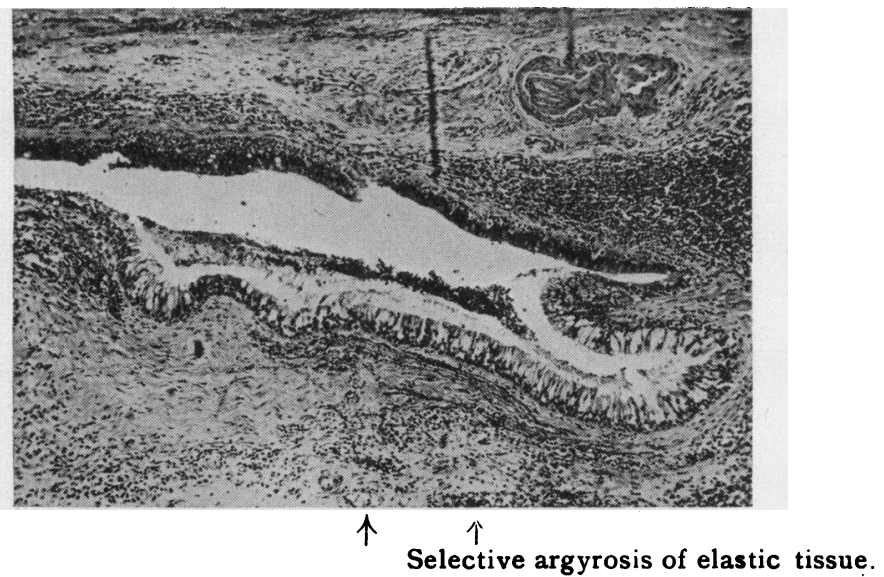

Fig. 4.

Argyrosis of the tear-sac (Haem.-Eosin). Low power.

Goblet cells of sac-epithelium. $\downarrow$

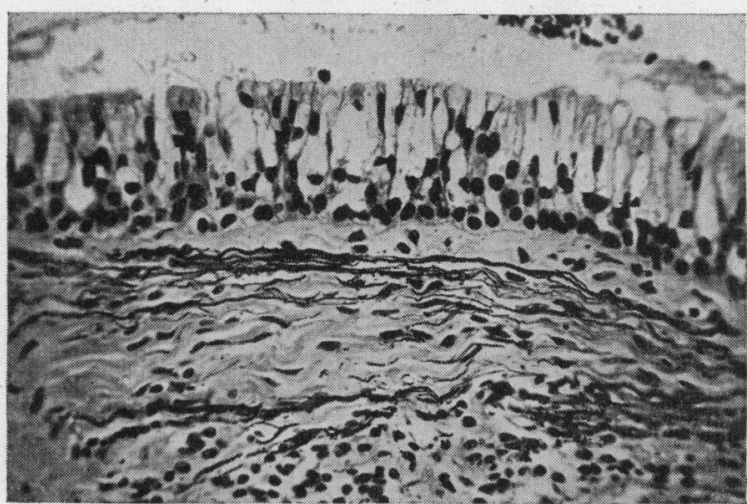

$\leftarrow$ silverfree subepithelial zone

$\leftarrow$ elastic slements

Fig. 5.

Argyrosis of the tear-sac (Haem.-Eosin). High power. 
were restricted to the surface of the fibres ( $a$ in Fig. 3). Some fibres were thin, the particles lying narrow, close to each other $(b)$. The tiniest were so thin that they were hardly visible, being marked by some particles at various distances $(c)$. Besides the silver covered fibres free particles were found, mostly within the deep layers. Endothelial cells of the capillary system contained very few silver grains. The sac had a narrow empty lumen (Fig. 4), its epithelium was partly mucous degenerated, partly thickened to $10-12$ rows, partly missing completely. Nowhere was there a trace of silver within the epithelium. Here as in the conjunctiva a narrow silverfree space was found (Fig. 5). The

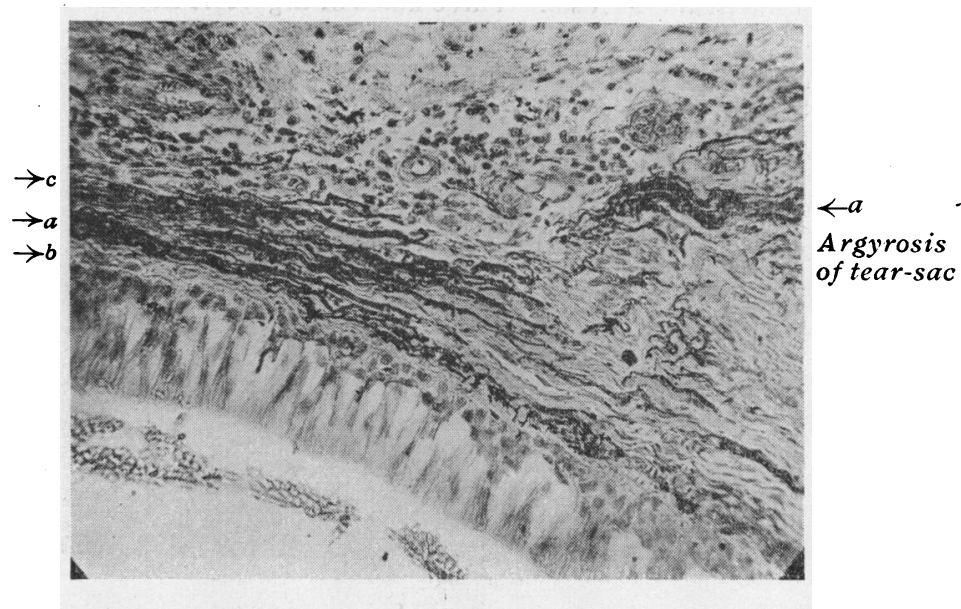

FIG. 6.

a. Selective staining of elastic fibres.

$b$. Brown granulated precipitates.

c. Shorter broken, punctate Ag. threads.

silver fibres underneath were richer than those of the conjunctiva, they ran mostly parallel to the epithelial surface, unequally distributed, but everywhere present in the slide round the lumen of the sac. They reached deeper than the conjunctival ones on the average $120 \mu$. Those close to the epithelium were of a brownish hue, the deeper ones were black. The elastic "ribbons" were thicker and longer than the conjunctival ones (Figs. 5, 6). There were more free particles. Some of them were thicker and aggregated to patches. Groups of thick patches black as china ink were packed subepithelially at certain spots. Endothelial cells of capillaries and precapillaries were partially filled with silver grains (Fig. 7). Some haemorrhages contained them too. Groups of large mast cells, some of them with a diameter of 12-17 $\mu$ (Figs. 8, 9 ), filled with equal, clear purple corpuscles and a light eosin-red 


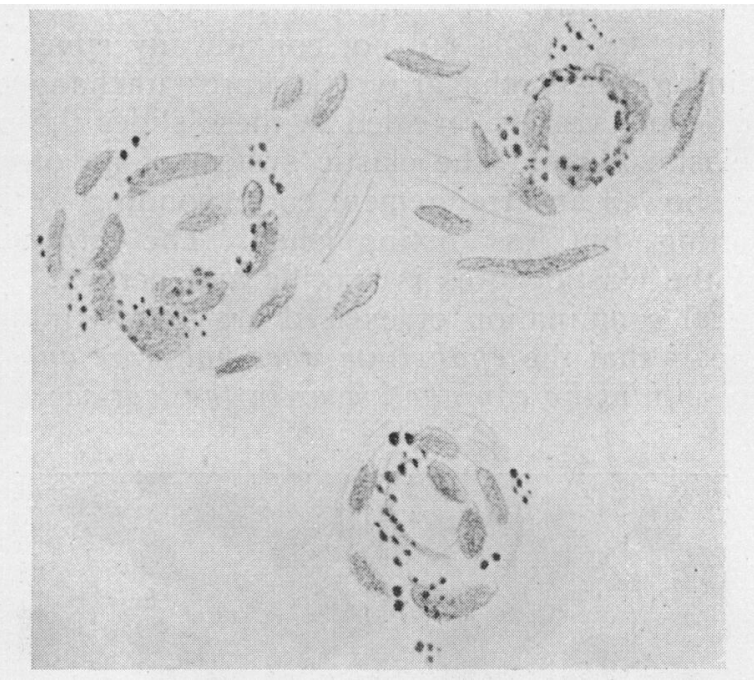

Fig. 7.

Endothelial phagocytosis-Argyrosis of tear-sac.

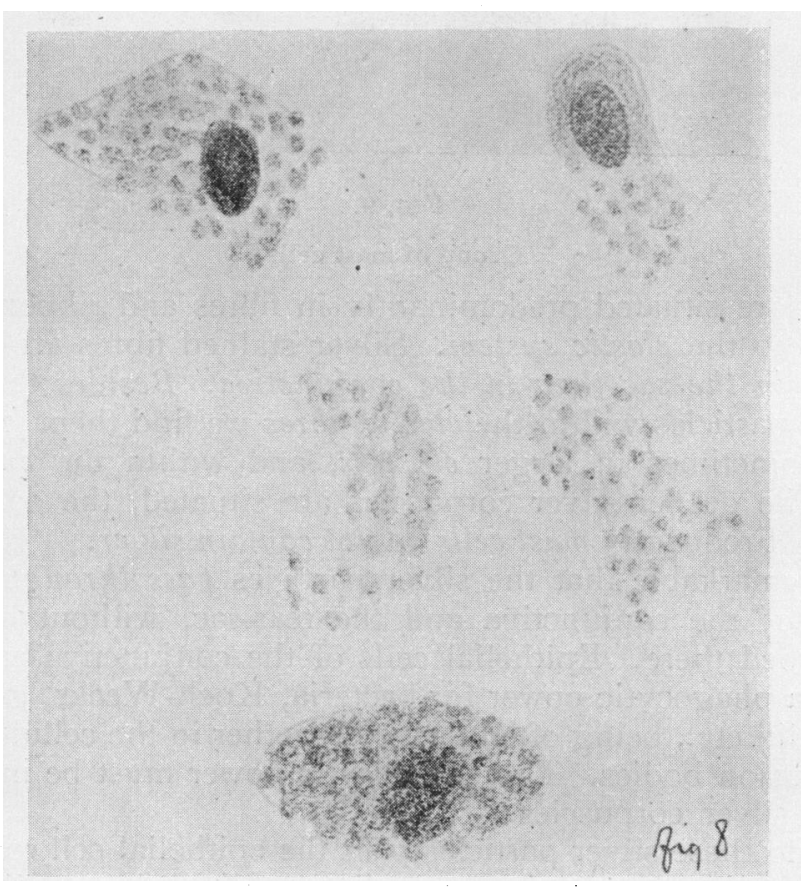

FIG. 8.

Mast cell groups in argyrotic sac. 
plasma were not rare. The nucleus of certain mast cells had vanished. The mast cells did not contain any silver corpuscles. Orcein staining leaves the argyrotic fibres unchanged. Cross sections of deeper vessels revealed in these slides the presence of silverfree elastic fibres. The elastic system of an orcein stained control sac showed an arrangement corresponding to the " intravital" staining, but less distinguished. The intra-vitam silver staining of the elastic fibres is specific and perfect.

Histological examination of excised argyrotic conjunctiva and tear-sac reveals that the epithelium does not store any silver particles either within the conjunctiva or in the tear-sac. The silver

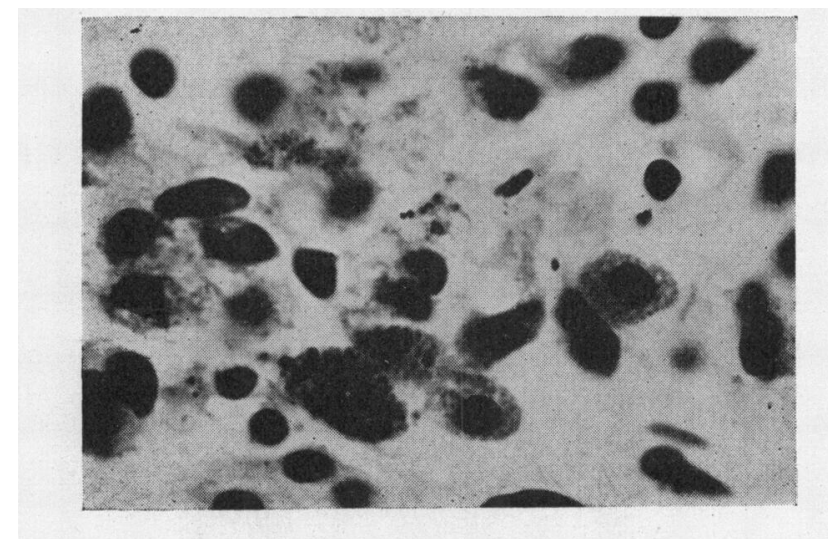

FIG. 9.

Group of mast cells.

particles are situated predominantly in fibres and ribbons corresponding to the elastic system. Silver stained fibres are far more frequent in the sac than in the conjunctiva. Besides the storage of silver particles within the elastic fibres we find them free in the tissue, sometimes in larger clusters, and within the endothelial cells. The deeper silver corpuscles are situated, the darker they appear. Frequently mast cells do not contain silver.

It is remarkable that the silver particles pass through the epithelium of the conjunctiva and the tear-sac, without being ador absorbed there. Epithelial cells of the conjunctiva are known to have a phagocytic power for bacteria, Koch-Weeks, gonococci, diplobacilli etc., being often packed together in the cellular plasma like inclusion bodies. This phagocytic power must be inconsiderable for silver corpuscles.

How do these silver particles pass the epithelial cell rows? We know that leucocytes rise immediately after the application of silver nitrate (unpublished own experiments). It may be that the silver particles are absorbed by the leucocytes which move actively 
through the epithelium into the subepithelial tissue, where they perish and liberate what they have engulfed.

The greatest part of the silver particles are bound to the elastic fibres; a much smaller part is situated free within the connective tissue; the rest are " phagocytised" by the reticulo-endothelial cells of precapillaries and capillaries.

The above mentioned selective staining of the elastic elements may be interpreted either as an adsorption, or as a chemical reaction. Purely physical adsorption at the surface of the fibres would correspond very well with our findings, especially with respect to the double lined thick fibres. Nevertheless I am more inclined to the second view, as an adsorption which functions so selectively towards one kind of tissue does not appear very probable.

Silver nitrate precipitates halogens $(\mathrm{Cl} . \mathrm{Br}, \mathrm{I})$ and sulphur. My conclusion was that $\mathrm{Ag}$ is precipitated as $\mathrm{AgCl}$. and possibly reduced under the influence of light to metallic silver.

The other possibility seems to be that $S$ containing cystin or cystein or one of its decomposition products reacts with the silver nitrate to form insoluble $\mathrm{Ag}_{2} \mathrm{~S}$, a black precipitate.

These suppositions are founded on interesting experiments of (W. Heubner, 1937) who implanted 0.1 to $0.2 \mathrm{~mm}$. silver platelets into corneal pockets of rabbits. These platelets were surrounded after some time by a tender connective tissue. Extirpation of the platelets with their sheaths and microchemical examination led to the discovery of black crystals which gave the reactions of silver sulphide. In between these there were found less frequently greyish white clusters of crystals which were proved chemically to be silver chloride. Both types of crystals look on simple microscopic examination like metallic silver. Heubner suggests that glutathione, a derivative of cystin, is present and represents the source of sulphur. It is easier to explain the effect of chlorides. On the other hand I could not trace an analytic investigation which would confirm the conclusion that elastic elements are richer in either sulphur or chloride than other tissues.

The following experiment was then carried out. A blenorrhoeic tear-sac was halved and the two halves brought into a 1 per cent. solution of silver nitrate. One of the halves was during this process exposed to light, the other one kept in the dark. Both pieces were then washed, embedded in paraffin and stained with haematoxylin and eosin. Most of the silver was found to be precipitated within the epithelial layer in large patches. In addition we also find many cells, both plasma cells and polynuclear leucocytes, covered with minute particles. The cellular boundaries are frequently defined sharply by thin lines of silver. There is no selective adsorption on elastic fibres and no difference between the exposed and the dark portion. 
In the case under discussion it is rather amazing that silver reached the tear-sac, although it was choked. When the sac was rinsed all the liquid regurgitated mixed with tough mucus. It was assumed that no aspiration from the conjunctival sac could take place in a choked and obliterated sac or duct. This obviously has been proved to be incorrect. A very tiny aperture may still have remained unclosed and thus a feeble aspirating function of the canaliculi preserved. As soon as the silver particles would reach the sac, they could be deposited in the wall owing to the stagnation of the sac contents. On the other hand even if the sac is completely separated from its duct, a canaliculus may suck up the silver solution during lid closure. The sac then may deliver its surplus during the next winking of the eye.

The deep greyish blue reflecting corneal zone with its coarse " grain " belongs to the region of Descemet's membrane. Knapová and Bruckner suggest in accordance with Vogt, that this appearance is due to the silvery impregnation of the tissue in front of Descemet's membrane, which is especially rich in elastic fibres (Seefelder's " true lamina elastica corneae "). No decision on this point is possible without anatomical examination of a case. My own histological experience with rupture Descemeti and lipoidosis bulbi (to be dealt with separately) has convinced me that the true elastic lamina of the cornea is actually a thin anterior lamina of Descemet's membrane.

It is remarkable that endothelial cells of the sac arterioles absorbed silver particles, while on the other hand large mast cells did not contain any. Plasma cells are not infrequently found in cases of blenorrhoea of the tear-sac. Of mast cells I could find no previous observation.

The "elastophilia" of silver as observed in this case offers new prospects of experimental work. As e.g., Ester Groenblad's syndrome (angioid streaks with pseudoxanthoma elasticum) has been proved to be an affection of the whole of the elastic system it would perhaps be useful to use silver compounds for the study of damage to the elastic system. We might even be able to blockade the whole of the elastic system by repeated intravenous application of silver compounds and thus eliminate its functions. Many other questions concerning the nourishment of ocular tissues and their metabolism may find their solution by such investigations.

\section{REFERENCES}

Ascher, K. W. (1924).-Klin. Monatsbl.f. Augenheilk., Vol. LXXIII, p. 414. Cistola-Boll. d Ocul., Vol. XVI, p. 637, 1937 ; Zentralbl.f. d. ges. Ophthal., Vol. XXXIX, p. 672.

FREYLER (1936).-Zeitschr. f. Augenheilk., Vol. XC, p. 226.

Heubner (1937).-Arch. Ital. Sci. Pharmac., Vol. VI, p. 555. 


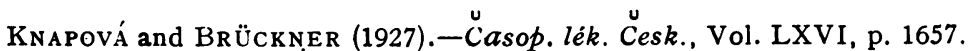

KotSU KA (1937).-Zentralbl.f.d. ges. Ophthal., Vol. XXXIX, p. 317.

PASTORE.-Soc. Oftal. Ital. 1925; Zentralbl. f. d. ges. Ophthal., Vol. XVII, p. 522.

Russo.-Rass. Ital. Oftal., Vol. VI, p. 72, 1937 ; Zentralbl. f. d. ges. Ophthal. Vol. XLI, p. 279.

SALUS (1917).-Wien. klin. Wochenschr., p. 1472.

VoGT (1929).-Klin. Monatsbl. f. Augenheilk., Vol. LXXXII, p. 433.

\title{
RETINOPATHIA CENTRALIS ANGIOSPASTICA (ANGIONEUROTICA), AND SEROSA ALLERGICA, AND THEIR RELATION TO DETACHMENT OF THE RETINA
}

\author{
BY \\ Professor ARnold Loewenstein, M.D. \\ (FROM THE TENNENT MEMORIAL INSTITUTE OF OPHTHALMOLOGY, \\ GLASGOW UNIVERSITY. PROF. A. J. BALLANTYNE)
}

CIRCUMSCRIBED disturbances of the retina, ophthalmoscopically recognisable, are found almost exclusively in the area of the macula, since a slight disturbance of function is not striking enough when a peripheral sector is concerned. A considerable number of such exudative processes in the macular area have been published as more or less rare solitary findings under different names. (Albrecht v. Graefe, Hirschberg, E. Fuchs, R. Batten, Kraupa, Asayama, Kitahara, Walsh and Sloan, Masuda, Oguchi, Guist, Reh, Hery, Junius, Stern, Suganuma, Kiewe and Reh, Cattaneo, Dollar, Abe, Bailliart, G. von Grolman, E. B. Streiff, Bangerta-Blaser, Avizonis. It is greatly to Horniker's credit (1929 and 1937) that he stressed the striking fact that the macular tissue is very easily injured by vessel disturbances. In several papers he described exactly the picture of retinitis centralis angioneurotica. Not infrequently narrowing of the capillaries of the retina, proved endoscopically, is the source of the affection. The present author himself has an experience of the astonishing figure of 72 cases, according to his last paper referring to this subject. They show a pathological form of reaction possibly of hereditary origin-an actual constitutional peculiarity. The angioneurotic constitution may have some connection with lues in the second and third generation (Kraupa), a question about which we are not yet well informed. The analogy to intermittent claudication, to migraine, to amaurosis partialis fugax and to bronchial asthma seems to be clear. Horniker measured the capillary pressure endoscopically with the ophthalmo-dynamometer. The visible rotating movement within the retinal blood vessels becomes slower under a certain pressure. 